2 电电

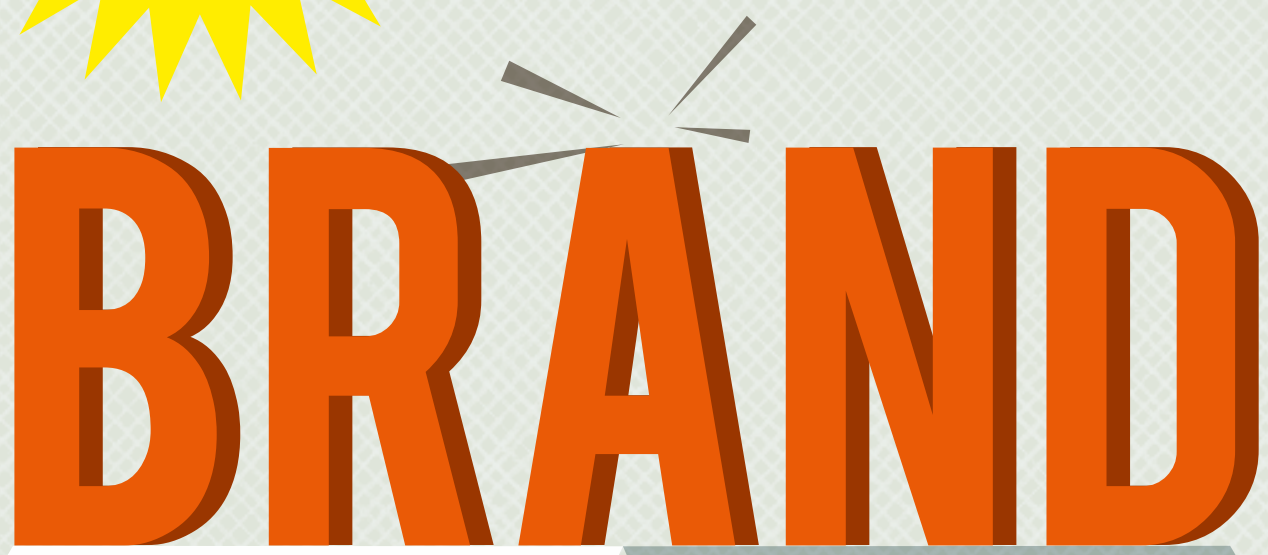

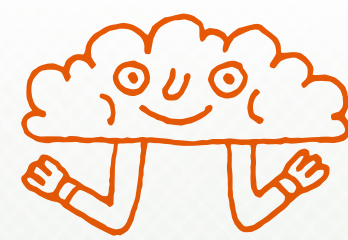

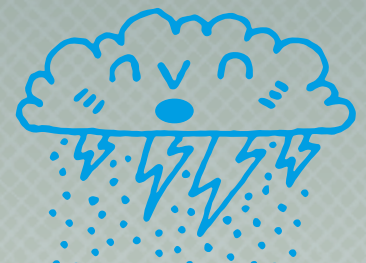

\#RETURN

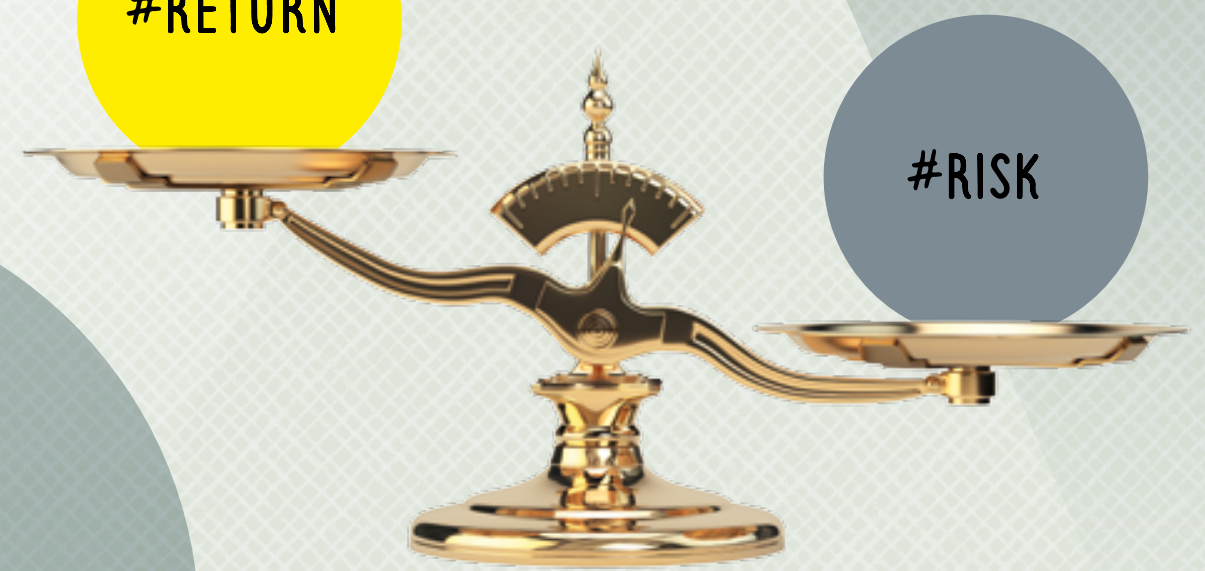




\title{
Branding and the Risk Management Imperative
}

\author{
Susan Fournier and Shuba Srinivasan
}

\section{KEYWORDS}

Brand Risk, Reputation Risk, Brand Dilution Risk, Brand Stretch Risk, Brand Cannibalization Risk, Socio-Economic Risk

THE AUTHORS

Susan Fournier

Senior Associate Dean,

Questrom Professor in Management, and Professor of Marketing,

Boston University, Questrom School of Business,

Boston, MA, USA

fournism@bu.edu

\section{Shuba Srinivasan}

Adele and Norman Barron Professor in Management, Professor of Marketing,

Boston University, Questrom School of Business,

Boston, MA, USA

ssrini@bu.edu
Every light has its shadow /// Of all the assets under marketing control, brands are perhaps the most valued. A strong brand attracts new customers, retains existing customers and offers a platform for the introduction of new products. A strong brand can reduce risk by encouraging broader stock ownership, insulating a company from market downturns, granting protection from product failures and reducing variability and volatility in future cash flows. A landmark study by Madden and colleagues confirms that by cultivating strong brand assets, companies not only generate greater returns but also do so with less risk. At the same time, a company's branding strategies can exacerbate its risk profile, thus endangering revenues, cash flows, brand equity and shareholder value. The history of the Martha Stewart Living Omni Media brand (Box 1) serves as an example highlighting the strategic role that brands play, not just in driving top-line revenue but also in implicating a company's risk exposure. Given that investors seek to maximize returns while minimizing risk exposure, it is crucial that management proactively considers brand-related risks. The problem is that marketers have only recently entered the risk conversation. If managers are to understand brands as tools for risk management, they need to understand four types of brand risk (Figure 2).

\section{Four brand-relevant risks}

Brand reputation risk $/ / /$ is the possible damage to a brand's overall standing that derives from negative signals regarding the brand. It destroys shareholder value by threatening earnings through negative publicity that exposes the companies to litigation, financial loss or a decline in its customer base. By selecting certain strategies, brands may become more exposed to reputation risk. Extensions into downscale markets endanger a brand's standing and damage a brand's quality associations or its perceived exclusivity. 
$\{$ Box 1$\}$

\section{THE RISE AND FALL OF MARTHA STEWART LIVING OMNIMEDIA, INC. (MSLO)}

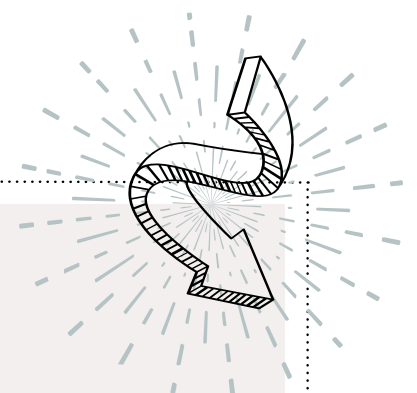

Martha Stewart first appeared on the cultural landscape in the late 1970 s as a caterer. She steadily built her reputation as a homemaking guru and expanded with a line of housewares sold through mass-market retailer K-mart in 1987. In 1990, Time-Warner took notice and launched the monthly Martha Stewart Living magazine. A media empire quickly grew and a lifestyle maven was born.

Martha Stewart Living Omnimedia (MSLO) went public in 1999 at $\$ 36.88$ a share. By 2001, Martha Stewart stood as a cultural icon and her eponymous lifestyle brand was one of the world's strongest. One short year later, MSLO traded as low as \$1.75 in the height of a scandal that eventually landed the founder in jail. MSLO never recovered. It was purchased in 2015 by brand management and licensing company Sequential Brands Group for $\$ 353$ million, at $\$ 6.15 /$ share. Although analysts highlight the benefits of authenticity and intimacy that came with Stewart's human brand, they also point toward the risks inherent in using a living person as the core of a brand.

FIGURE 1:

\section{MSLO Stock price evolution from IPO to Sale}

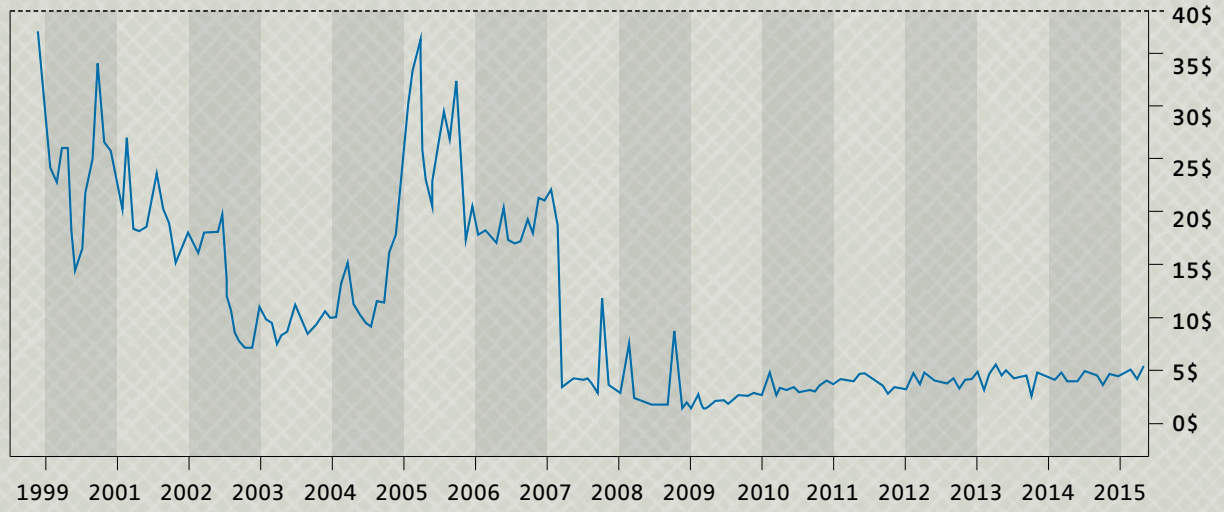

From: https://finance.google.com/finance/historical?q=NYSE:MSO

https://finance.yahoo.com/

Connecting a large portfolio of products with one single brand name and logo can make brands vulnerable to this type of spillover risk. As the piece by Fournier and Eckhardt (pp. 30) demonstrates, reputation risk is exacerbated through personbrand strategies, as for Calvin Klein and Martha Stewart. They highlight the importance of consistency and balance between the person and the brand. Misconduct within a company poses risk, also for non-person brands. Consider Uber, the highest valued pre-IPO firm in history. It suffered financial losses and was downgraded $16 \%$ by mutual funds following a series of high-profile reputational crises involving CEO Kalanik and the Uber organizational culture. In a similar way, celebrity endorsements expose brands to spillover reputation risk. Research on the Tiger Woods scandal links celebrity 
endorsement not just to stock market effects but also to damage affecting the entire companies of the sponsors.

The contemporary marketing landscape with ongoing cocreation, social media interconnectedness and fake news increases reputation risk even more. The article by Berthon, Treen and Pitt (pp. 18) illustrates how truthiness, fake news and a "post-fact" culture endanger brands and increase brand risk and proposes several solutions for risk management.

Brand dilution risk /// concerns the loss of meanings that differentiate a brand from its competition. Brand differentiation, more than any other brand quality, drives market share and penetration. Conversely, losses in brand differentiation comprise the first step in the erosion of brand equity. The loss of unique brand meanings negatively affects cash flows because customers might switch to other brands or become unwilling to pay price premiums. The frequency, depth, range and quality of brand extensions increase a company's exposure to dilution risks. Consider Harley Davidson's decision to enter the food category and introduce beef jerky: Line extensions serving the current category with new varieties or category extensions into markets not previously served distance the brand from what is unique about it in consumers' minds and dilute the brand. Nabisco's introduction of Watermelon Oreos is another example: Focal meanings of the Oreos brand become diluted as the new extension adds additional meanings relating to watermelon flavor that must somehow be accommodated in the brand's meaning mix. Burger King's launch of its so-called "healthy" Satisfries, complete with salt and grease, has the potential to obliterate the favorable and dominant brand associations that drive the strength and value of the Burger King brand.

Companies with multiple offerings in a category also risk dilution simply because such brands are more likely to overlap and lack distinctiveness in consumers' minds. Mercedes' C-class stands as a powerful case in point. As Chip Walker's article (pp. 24) shows, new brand and line extensions raise awareness but can add risk when such knowledge makes people think worse of the brand. As Monga and Hsu (pp. 40) point out, culture and its associated style of thinking is a powerful predictor of how consumers react to brand extensions and companies need to consider culture carefully when leveraging and protecting brands.
Brand cannibalization risk /// leads to sales or revenue losses that accrue when customers buy a new product at the expense of other products offered by the same company. Cannibalization, or intra-brand substitution, is a type of spillover risk and managers strive to minimize competition within product lines. Multiple line extensions within the same category risk considerable overlap in their brands' value propositions and poorly differentiated brands suffer greater cannibalization. On page 34 Mason and Jayaram explain the dynamics of cannibalization risk and recommend investigating factors that drive cannibalization, measure the cannibalization effect on existing products and consider organizational implications.

Fighting brands such as Kodak's FunTime film, designed for "less important" photographic occasions, attempt to defend a company against price-based competitors but can exacerbate cannibalization risk when they substitute other brand offerings. Vertical line extensions into value-based markets, such as Porsche's introduction of the Cayenne model, incur the same risk. They become counter-productive from a margin standpoint when customers who would otherwise purchase the costlier version trade down to the cheaper alternative. Tesla's

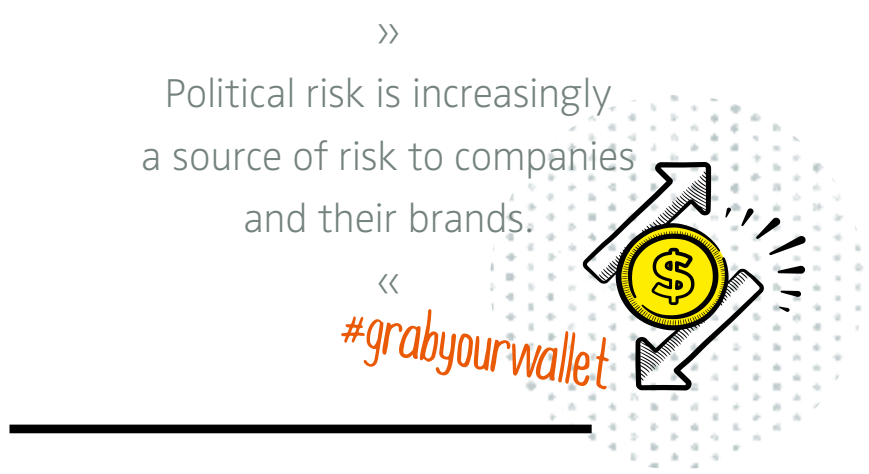

introduction of the Model 3 provides a case in point with investors foreshadowing the erosion of the Tesla brand at the hand of profit declines. Also, luxury fashion houses launching lowprice/low-quality fighting brands are entering a slippery slope. Experts generally agree that there can be negative spillover risks to the main brand, although new clients can be cultivated. Outlet channels present a similar dilemma: Louis Vuitton is not available at the outlets, but Burberry and Armani are. The trade-off between reaching more customers and keeping brand values is difficult to balance. Access to upscale markets 
FIGURE 2:

\section{Types of brand risk and their drivers and effects in today's market reality}

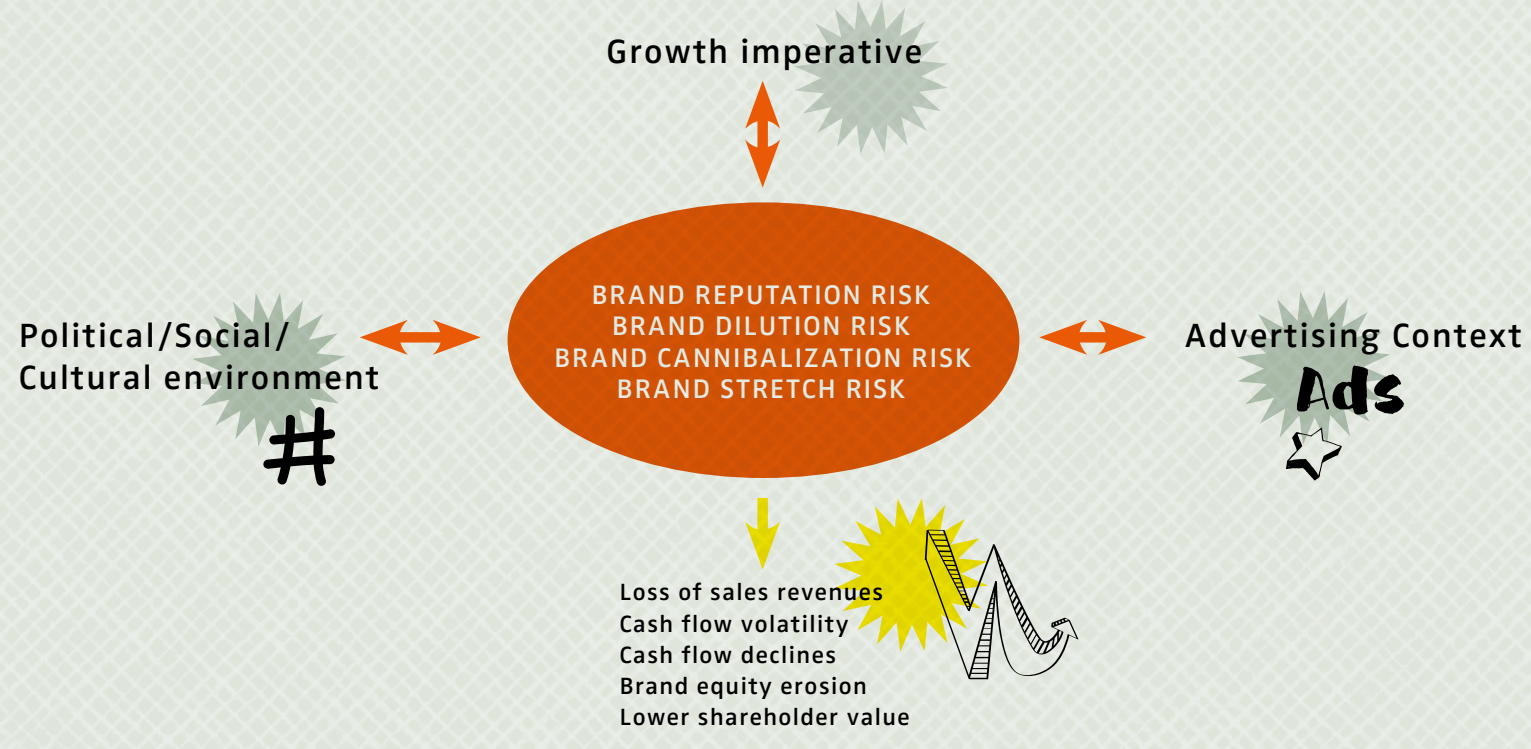

through supra-branding, as Volkswagen attempted with the Phaeton, is also high risk as this strategy often pushes the brand beyond its natural boundaries.

Brand stretch risk /// reduces a company's ability to take advantage of new market opportunities, new technologies or changing consumer tastes through the introduction of new, tailored offerings. A main motivation for building a brand is to leverage it, but certain brand meaning characteristics can increase a company's exposure to brand stretch risk. A brand with concrete meanings has less room to grow and hence greater stretch risk. Coach recently rebranded itself as Tapestry to allow for growth beyond the leather handbags and accessories that have borne the Coach brand name.

Dominant meanings tied to a specific category - such as with Kleenex and tissues or Levi's and jeans - further limit opportunities and increase stretch risk. A brand can also face growth restrictions through dominant meanings that strain the credibility of new offerings. American restaurant chain Hooters' decision to launch an airline was ill fated because its dominant association with frivolity clashed with the need for safety in air travel.

New realities enforce the need to manage brand risk

Risk management is not a natural act for brand managers trained in astute execution of the 4 Ps to drive revenues, and contemporary market factors make this more challenging still.

Brands and politics: a risky couple /// Anyone familiar with risk management within the world of economics and finance understands political risk as a macroeconomic factor affecting certain markets as a whole: The geopolitical instability in the Middle East, censorship of information in China, or the turmoil in the EU caused by Brexit all pose systematic risks to global brands. What is less obvious is that political risk is increasingly a source of risk to companies and their brands. The politically-charged environment created in the United States around Trump's presidency has made every news story an opportunity for brand meaning making. Whether unintended or intended, political affiliation has looming consequences for dilution and reputation risks. Movements such as "Grab Your Wallet," founded in response to Trump's treatment of women, encouraged a boycott of Trump-branded products and companies associated with Trump. Even distant personal connections to Trump have increased brand risk and destroyed brand value in associated companies. A boycott against L.L.Bean was initiated after Linda Bean, one of the 50 family members associated with the company, donated money to the Trump campaign. The Carrier and Ford brands were caught in the crosshairs of a debate to build a wall between Mexico and the U.S. and 


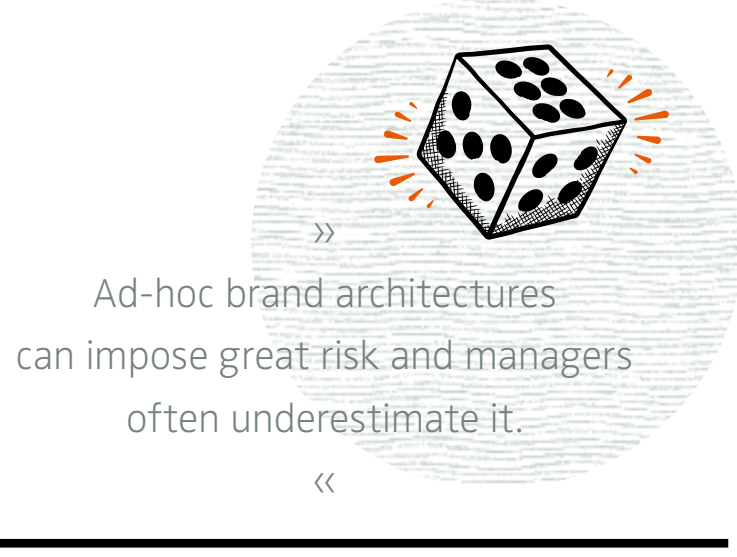

shift manufacturing stateside. The pull of brands into the political arena extends beyond reactions to the current U.S. presidential office to a more hyper-charged cultural world. Nike, Adidas, Under Armour and others found themselves in political territory after President Trump decided to take a public stance against NFL players who failed to stand for the U.S. national anthem. Weinstein Productions, The New York Times, National Public Radio's Prairie Home Companion and Charlie Rose, NBC's Today Show; a short list of media brands embroiled in nationwide political debates in the wake of highprofile sexual harassment scandals.

What is interesting is that some brands are willingly injecting themselves into this contested environment. They ignore the well-worn advice that brands won't do well when they involve themselves in ideologies. Politics polarize and most likely alienate a portion of a brand's customer base. Starbucks felt compelled to react to Trump's immigration ban by announcing that it would hire 10,000 refugees in its stores worldwide. Lyft stood firmly against the ban on immigrants and made a $\$ 1$ million donation to the American Civil Liberties Union, while rival Uber took a hit for its seemingly opportunistic response. Managers need to be cognizant of how exposed their brands are to political risk and how social media might intensify the risks before stepping into the political realm. With an increasingly polarized society, it may be impossible for brands to remain untouched by ideologies. Our interviewee Patrick Marrinan stresses that being right for half of the people means being wrong for the other half and suggests strategies for managing increasing social-political risk (pp. 52).

Less control over advertising context /// With the growth in digital advertising, brand managers increasingly have less control over advertising placement and context. In the traditional brand-building world, managers controlled media exposure by targeting particular demographics and refining content to optimize brand messaging. BMW carefully placed its Z3 in James Bond movies to emphasize synergistic associations and target audience characteristics between the BMW
$\{$ Box 2$\}$

\section{TEN KEY QUESTIONS TO HELP MANAGERS ASSESS BRAND RISK}

1. Is your product category or brand heavily exposed to political risk?

2. Judging from social media and press mentions, is your brand significantly embedded in the cultural conversation?

3. Are your brand's dominant meanings narrow in scope and tied to a particular product category?

4. Is your brand heavily extended across multiple lines, a broad range of price points, or over multiple categories?

5. Is the level of consumers' brand knowledge and awareness higher than the level of brand liking?

6. Is your brand strongly interconnected with a human such as a founder or celebrity endorser?

7. Does your CEO or company founder have a blog or other public venue through which s/he regularly communicates with the public and media?

8. Does your brand management team lack professionals skilled in crisis communications, media and public relations and the legal side of risk management?

9. Is a high portion of your advertising budget for consumer traffic spent on digital advertising?

10. Does your brand architecture connect brand offerings under the same brand umbrella?

The more often your answer is "yes, " the more exposed your brand will be to brand risk. Each individual "yes" demands attention and thoughtful management intervention to prevent possible brand damage.

and James Bond brands. Today's digital world is different, and placements result from programmatic algorithms driven by consumer histories rather than managerial decisions. Such consumer-initiated ad targeting introduces vulnerabilities. For example, $P \& G$ found its brands on extremist websites on YouTube, prompting a $\$ 140$ million reduction in digital advertising spending. 
FIGURE 3:

\section{Mindset qualities to manage brand risk successfully}

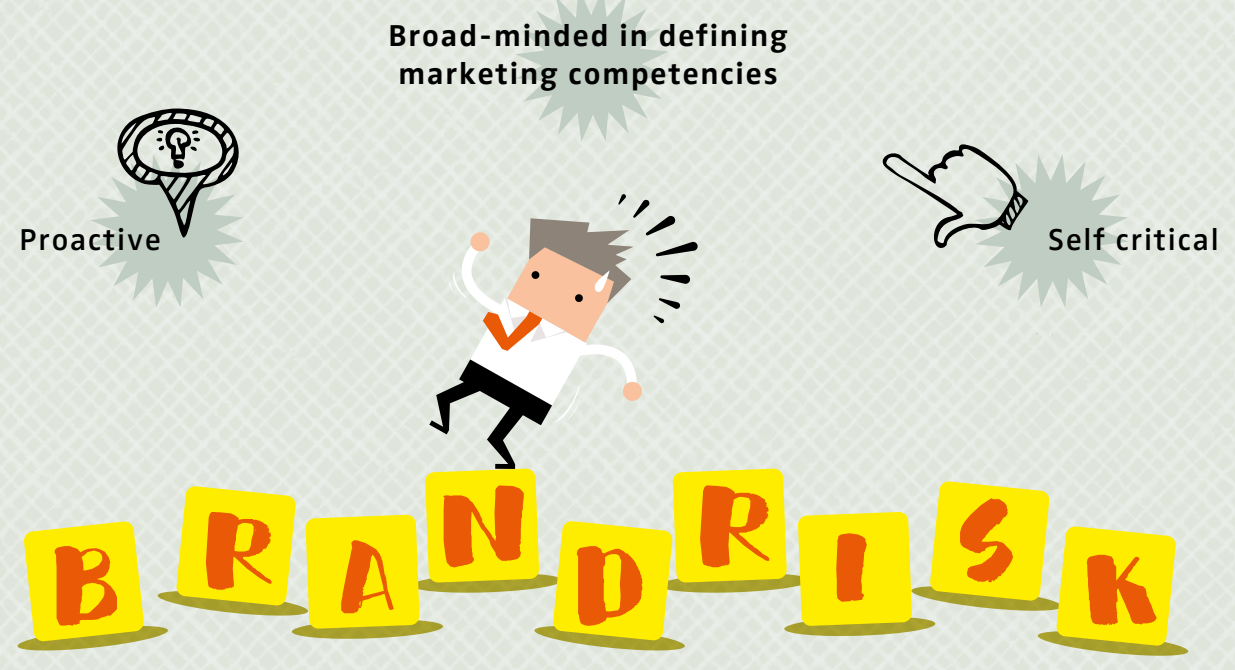

Brand managers face a choice: They can follow the digital traffic and accept attendant consequences of higher risks and potentially higher rewards, or they can attempt to manage the seemingly uncontrollable by imposing increased vigilance. Abdicating responsibility to machine learning requires ad placement monitoring solutions that minimize brand reputational risk. Managers can also manage risk exposure through a balanced advertising portfolio that combines company-initiated traditional advertising with better control over placement with digital advertising offering better consumer targeting, albeit with less context control.

The growth imperative /// Driven by the shareholder imperative of driving growth in revenues, companies have become addicted to opportunities that expand their brand portfolios through mergers and acquisitions, new product introductions and line extensions. How new brands are incorporated into existing ecosystems - what is known as brand architecture strategy - is often ad-hoc rather than strategic and planned. These ad-hoc architectures can impose great risk and managers often underestimate it.

Our research shows that in contrast to predictions from marketing research, a sub-branding structure such as Apple's i-products or BMW's 7-, 5- and 3-series does not control risk, but in fact exacerbates it. This strategy registers the highest risk profile of all architectures. Managers pursuing subbranding perceive a false sense of protection against risks of overextension, dilution and cannibalization. The reality is that the very qualities that commend this strategy - its ability to encourage broader participation in markets and extensions that are farther afield from the base brand - exacerbate risk. Endorsed branding architectures like Post-it Notes by $3 \mathrm{M}$ create distance from the corporate brand. These are effective risk control mechanisms, but costs for building what are in effect two brands are higher and associated with returns lower in response. Managers who seek ultimate risk control are advised to pursue the house-of-brands strategy with different brand names, albeit with costs to returns. If managers think they can control risk by diversifying brand architecture strategies, they should think twice: The hybrid mix does not offer enhanced risk control.

How to successfully integrate a risk perspective into branding /// Managing brands by managing risk is inherently different from managing brands according to a revenue rubric. The more exposed your brand is to brand risk (see Box 2 to assess your risk potential), the more attention this topic will need in your boardroom. Three mindset qualities are relevant in shifting marketing philosophy toward risk. 
$>$ Be broad-minded in defining marketing competencies /// The risk-savvy brand manager needs to rethink the skills that define marketing competency. Crisis management is the backbone of the playbook, but in today's hyper-sensitive marketplace, crisis management skills are not "emergency resources." They are called upon to negotiate consumers' brand meaning making each and every day. Ours is a world where threats to brand value can come in a lone tweet, a Facebook post, or a celebrity blog. Identify the specific risks confronting your brand. Estimate the potential for those risks. Determine a crisis response action plan. When training brand managers, take lessons from public relations and media professionals who truly understand how to embed brands in the fabric of daily living. Engage legal professionals skilled in the art and science of risk management. Enrich your management team with sociologists who understand the nature and dynamics of co-created brands.

$>$ Be self-critical /// Risk management focuses on the negative - threats, weaknesses and vulnerabilities rather than opportunities that drive top-line results. This requires a managerial mindset that is self-critical, a willingness to accept that conventional wisdom might not hold. In the world of risk, awareness can be harmful. Brand extensions can destroy brand assets. Brand risks may not diversify through a mixed portfolio strategy. The risk manager must take care not to assume in a game whose rules are changing. Thoughtful after-action reviews will provide needed insight into failed strategies.

$>$ Be proactive /// Effective brand risk management requires managers to think systematically about the types of risks facing their brands. A risk assessment will reveal not only individual vulnerabilities but also category differences in inherent risk profiles, and this will inform marketing actions. Luxury brands are more susceptible to dilution risk than any other category because of their exclusivity associations. Lifestyle brands are exposed to greater reputation risk because they tap deep, sometimes hotly-charged cultural values. Person brands such as Martha Stewart face a completely different set of risks as compared to packaged good brands: persons die, they have families and friends, they act spontaneously, and these human qualities affect risk-return profiles. The type of relationship that consumers form with a brand also matters from a risk perspective. Hupp, Robbins and Fournier (pp. 58) identify "at-risk" relationships that need special attention in times of crisis to stem the loss of brand value. Hanssens, Fischer and Shin (pp.46) note that marketing managers need insight into how marketing decisions affect cash flow volatility, and offer recommendations on how volatility risk can be monitored and managed.
Opportunities and risks in brand management are as inextricably linked to each other as light and shadow. Being aware of the shadow - its possible shapes, its different intensities and all the angles it can emerge from - will cultivate preparation and prevent stumbling in the dark.

1.

\section{FURTHER READING}

\author{
Fournier, Susan and Avery, Jill (2011): \\ "The Uninvited Brand," \\ Business Horizons, Special Issue: \\ Social Media, 54 (May/June), $193-207$.
}

\section{Hsu, Liwu; Fournier, Susan and} Srinivasan, Shuba (2016):

"Brand Architecture Strategy and Firm Value:

How Leveraging, Separating, and Distancing the Corporate Brand Affects Risk and Returns,"

Journal of the Academy of Marketing Science,

$$
44 \text { (2), } 261-280 .
$$

\section{Madden, Thomas J.; Fehle, Frank and Fournier, Susan (2006):}

"Brands Matter: An Empirical Demonstration of the Creation of Shareholder Value through Brands," Journal of the Academy of Marketing Science,

$$
34 \text { (2), 224-235. }
$$

Srinivasan, Shuba and Hanssens, Dominique M. (2009):

"Marketing and Firm Value: Metrics, Methods, Findings and Future Directions,"

Journal of Marketing Research, 46 (3), $293-312$.

\section{Srinivasan, Shuba; Hsu, Liwu and Fournier, Susan (2012):}

"Branding and Firm Value,"

The Handbook of Marketing and Finance, S. Ganesan and S. Bharadwaj (eds.), Northampton, MA:

Edward Elgar Publishing, 155-203. 